ISSN 2089-8673

Jurnal Nasional Pendidikan Teknik Informatika (JANAPATI)

Volume 2, Nomor 1, Maret 2013

\title{
PENGENDALIAN MOBILE ROBOT MENGGUNAKAN PERSONAL COMPUTER DENGAN KONEKSI BLUETOOTH
}

\author{
Oleh \\ I Made Suradana, I Wayan Sudiarsa \\ Program Studi Sistem Komputer \\ STMIK STIKOM INDONESIA \\ Email: suradana.made@gmail.com, sudiarsa@gmail.com
}

\begin{abstract}
ABSTRAK
Perkembangan teknologi yang semakin pesat khususnya dalam bidang perkembangan robot yang menjadikan kualitas kehidupan manusia semakin tinggi. Robot dikembangkan tidak lain untuk mempermudah pekerjaan manusia. Dalam dunia robot terdapat kategori mobile robot. Mobile robot adalah robot yang dapat bergerak atau berpindah tempat dan dapat dikendalikan secara otomatis atau manual.

Mobile robot yang dapat dikendalikan user menggunakan komputer sebagai interface pengendaliannya. Untuk menghubungkan mobile robot dengan komputer saat ini menggunakan kabel. Tentunya banyak kekurangan dalam penggunaan kabel sebagai media penghubung pengendalian mobile robot misalnya seperti terbatasnya gerakan mobile robot dari panjang kabel, kabel cepat rusak karena sering terjadinya tekukan pada kabel dan robot terlihat kurang menarik. Berkaitan dengan hal itu, bagaimana jika penghubung antara mobile robot dengan komputer tanpa menggunakan media kabel melainkan menggunakan teknologi tanpa kabel yang saat ini telah mengalami perkembangan yang pesat.

Pada makalah ini mobile robot yang dibuat menyerupai tank. Dengan menggunakan akrilik sebagai body mobile robot yang menjadikan mobile robot terlihat menarik. Board arduino yang dilengkapi mikrokontroler AVR Atmega8 diprogram dengan menggunakan software codevisionavr. Penggerak mobile robot menggunakan twin gearbox motor dc yang ditempatkan pada posisi belakang mobile robot.

Setelah dilakukan pengujian mobile robot didapat waktu tempuh rata-rata mobile robot bergerak maju dalam jarak 1 meter adalah $0,154 \mathrm{~m} / \mathrm{s}$ dan waktu rata ï rata yang diperlukan mobile robot untuk melakukan putaran sebesar 3600 adalah 2,48 detik.

Kata-kunci : Mobile robot, Bluetooth, Mikrokontroler AVR Atmega8
\end{abstract}


ISSN 2089-8673

Jurnal Nasional Pendidikan Teknik Informatika (JANAPATI)

Volume 2, Nomor 1, Maret 2013

\section{PENDAHULUAN}

\subsection{Latar Belakang Masalah}

Seiring dengan perkembangan teknologi yang sangat pesat khususnya dalam bidang perkembangan robot yang menjadikan kualitas kehidupan manusia semakin tinggi. Berbagai robot telah di kembangkan khususnya dalam bidang mobile robot. Mobile robot adalah robot yang dapat bergerak atau berpindah tempat. Mobile robot dapat dikendalikan secara otomatis maupun pengendalian secara manual yang menggunakan PC dalam pengontrololan robot. Mobile robot yang dibuat baik dalam pengendalian otomatis atau manual di sesuaikan dengan kebutuhan manusia yang tentunya bertujuan agar mempermudah manusia melakukan pekerjaan sehari-hari.

Mobile Robot yang di kendalikan secara manual saat ini menggunakan kabel sebagai penghubung ke PC. Tentunya terdapat banyak kekurangan dalam penggunaan kabel sebagai media penghubung pengendalian mobile robot misalnya seperti terbatasnya gerakan mobile robot dari panjang kabel, kabel cepat rusak karena sering terjadinya tekukan pada kabel dan robot terlihat kurang menarik.

Dari permasalahan diatas maka penerapan teknologi Bluetooth sebagai media penghubung mobile robot ke PC terdapat banyak keunggulan. Bluetooth biasanya hanya dikenal sebagai media transfer data dan sangat jarang digunakan sebagai pengendali perangkat keras. Dengan pemanfaatan Bluetooth sebagai media penghubung pergerakan mobile robot tentunya terdapat banyak keuntungan baik dalam segi pergerakan maupun penampilan mobile robot.

\subsection{Rumusan Masalah}

Berdasarkan latar belakang di atas maka dapat diambil rumusan permasalahan sebagai berikut :

1. Bagaimana merancang mobile robot supaya dapat dikendalikan user menggunakan personal computer?

2. Bagaimana menggunakan teknologi Bluetooth sebagai koneksi pengendalian mobile robot?

\section{LANDASAN TEORI}

\subsection{Pengertian Robot}

Menurut Suyadhi (2008), ñRobot adalah mesin hasil rakitan manusia yang bisa bekerja tanpa mengenal lelah. Awalnya robot diciptakan untuk menggantikan tenaga manusia.ò

Menurut Widodo Budiharto(2010), òRobot berasal dari bahasa Czech, robota, yang berarti bekerja. ò

Menurut Budiharto(2010), r̃Pada tahun 1770, Pierre Jacquet Droz, seorang pembuat jam berkebangsaan Swiss membuat tiga boneka mekanis. Uniknya, boneka tersebut dapat melakukan fungsi spesifik, yaitu dapat menulis, yang lainnya dapat memainkan musik dan organ, dan yang ketiga dapat menggambar.ò 
ISSN 2089-8673

Jurnal Nasional Pendidikan Teknik Informatika (JANAPATI)

Volume 2, Nomor 1, Maret 2013

Menurut Budiharto(2010), òMobile robot adalah robot yang dapat bergerak, umumnya menggunakan kaki atau roda dalam pergerakannyaò

\subsection{Dasar-dasar Elektronika}

Dalam pembahasan mengenai elektronika dasar. Hanya membahas beberapa komponen yang berkaitan dengan pembuatan mobile robot yang akan dibuat diantaranya meliputi :

- Mikrokontroler

Menurut Budiharto(2010), ก̃Pemrograman mikrokontroler merupakan dasar dari prinsip pengontrolan kerja robot, dimana orientasi dari penerapan mikrokontroler ialah untuk mengendalikan suatu sistem berdasarkan informasi input yang diterima, lalu diproses oleh mikrokontroler, dan dilakukan aksi pada bagian output sesuai program yang telah ditentukan sebelumnya.ò

- Resistor

Menurut Suyadhi (2008), ñResistor adalah komponen dasar elektronika yang digunakan untuk membatasi jumlah arus yang mengalir dalam suatu rangkaian.ò

Kapasitor

Menurut Suyadhi (2008), ñKapasitor adalah komponen elektronika yang dapat menyimpan muatan listrik.ò

- Diode

Menurut Suyadhi (2008), ñDiode memiliki fungsi yang unik, yaitu hanya bisa mengalirkan arus dalam satu arah saja.ò

- Light Emitting Diode ( LED )

Menurut Suyadhi (2008), ñLED merupakan komponen yang mampu mengeluarkan emisi cahaya.ò

- RS-232

Menurut Rangkuti(2011), ñRS-232 merupakan seperangkat alat yang berfungsi sebagai penghubung ( interface) dalam proses transfer data antar computer atau antara computer dalam perangkat lain dalam bentuk komunikasi serial.ò

- MAX232

Menurut Rangkuti(2011), ñMAX232 mengonversi level tegangan RS-232 ke level tegangan TTL.ò

- Motor DC

Menurut Budiharto(2010), ñMotor arus searah (DC) adalah suatu mesin yang berfungsi untuk mengubah tenaga listrik arus searah menjadi gerak atau energy mekanik.ò

\subsection{Bluetooth}

Menurut Supriyanto(2006), ñBluetooth adalah sebuah teknologi komunikasi wireless (tanpa kabel) yang beroperasi dalam pita frekuensi 2,4 GHz unlicensed ISM (Industrial, Scientific and Medical) dengan menggunakan sebuah frequency hopping tranceiver yang mampu menyediakan layanan 
ISSN 2089-8673

Jurnal Nasional Pendidikan Teknik Informatika (JANAPATI)

Volume 2, Nomor 1, Maret 2013

komunikasi data dan suara secara real-time antara host-host bluetooth dengan jarak jangkauan layanan yang terbatasò

\subsection{Personal Komputer ( PC )}

Menurut Jogiyanto.(2005),ò Istilah komputer ( computer ) diambil dari bahasa latin computare yang berarti menghitung.ò

\subsection{Bahasa Pemrograman}

- CodeVisionAVR

Menurut Rangkuti(2011), ñCodeVisionAVR adalah compiler $\mathrm{C}$, yang telah dilengkapi dengan fasilitas Integrated Development Environtment (IDE) dan didesain agar dapat menghasilkan kode program secara otomatis untuk mikrokontroler Atmel AVR. Program ini dapat berjalan dengan menggunakan sistem operasi Windows 2000, XP, Vista dan Window 7.ò

- Terra Term

Menurut Maisuradze (2004), ñTerra term adalah open source software terminal emulator ( comunacation program ) untuk MS-Windows. ò Terra term merupakan emulator dari berbagai jenis terminal, dari VT100 sampai VT382 dan supports Telnet, SSH1, SSh2 dan Serial Port connections. Terra term dibuat dengan bahasa Macro Sripting.

\section{ANALISA DAN PERANCANGAN SISTEM}

\subsection{Analisa Sistem}

Mobile robot dirancang agar dapat dikendalikan komputer dalam pergerakannya sehingga dibutuhkan koneksi antara mobile robot dengan komputer. Dalam koneksi mobile robot dengan komputer menggunakan teknologi tanpa kabel. Yaitu dengan menggunakan teknologi bluetooth. Kelebihan dari penerapan teknologi tanpa kabel selain menjadikan mobile robot terlihat menarik, teknologi tanpa kabel juga memiliki keunggulan yang lain yaitu sinyal yang dapat menembus dinding, kotak, dan rintangan-rintangan lain sehingga mobile robot dapat menempuh banyak medan.

Alat yang dirancang terdiri dari dua bagian utama, yaitu komputer dan mobile robot. komputer berfungsi untuk mengirimkan data yang digunakan untuk mengendalikan jalannya mobile robot dengan media Bluetooth. Dimana Komputer mengubah hasil pengetikan menjadi data serial. Kemudian USB bluetooth mengubah data tersebut menjadi sinyal bluetooth, agar dapat diterima oleh serial bluetooth pada mobile robot. Sebaliknya, USB bluetooth juga dapat menerima sinyal bluetooth dari serial bluetooth pada mobile robot, dan mengubahnya menjadi data serial sehingga dapat diproses pada komputer

Keyboard sebagai interface pengendali dimana user dapat mengontrol pergerakan mobile robot dengan menekan tombol maju, mundur, kiri dan kanan. data yg di kirim dari keyboard ke komputer selanjutnya di kirim ke 
ISSN 2089-8673

Jurnal Nasional Pendidikan Teknik Informatika (JANAPATI)

Volume 2, Nomor 1, Maret 2013

mikrokontroler. Data yang diterima dari mikrokontroler diproses dan di kirim ke driver motor untuk menggerakkan roda mobile robot.

\subsection{Perancangan Elektronik}

- Mikrokontroler AVR Atmega8

Pada makalah ini digunakan mikrokontroller ATmega8 sebagai pengolah informasi. ATmega8 cukup handal sebab sudah memiliki ADC, port I/O dan juga komunikasi serial untuk dapat digunakan sebagai komunikasi antara mikrokontroler ke PC. Di gunakannya ATmega8 pada makalah ini karena pada makalahini tidak terlalu dibutuhkan banyak port. Port yang digunakan adalah port ADC sebagai port input dan beberapa port lainnya yang disetting sebagai port output.

Pemrograman secara In System Programming adalah programmer tidak perlu melepas IC mikrokontroller pada waktu akan di-download-kan, hal ini berarti pendownload-an program dapat langsung dilakukan pada rangkaian aplikasi. Yaitu dengan memanfaatkan pin-pin pada mikrokontroller ATmega8.

- Serial Bluetooth

Pada mobile robot di pasang serial Bluetooth. Serial bluetooth adalah modul bluetooth yang hanya berfungsi sebagai port serial jadi dalam kata lain modul ini akan menghubungkan port serial komputer dengan port serial yang terdapat dimodul bluetooth secara wireless(tanpa kabel). Modul ini hanya bisa beroperasi sebagai slave bluetooth, artinya modul ini tidak bisa bekerja jika tidak ada sinkronisasi (pairing) dari master, dalam hal ini komputer atau modul bluetooth lainnya yang dapat beroperasi sebagai master.

- Motor DC

Mobile robot yang di bangun mempunyai dua buah motor DC yang masing ï masing terhubung dengan roda bagian kiri belakang dan bagian kanan belakang dari mobile robot tersebut. Kedua motor DC ini menjadi penggerak utama mobile robot. Untuk memudahkan dalam menggerakkan roda mobile robot pada motor DC dipasangkan sistem gear box.

\subsection{Perancangan Sistem}

Dalam perancangan sistem dibahas mengenai software yang digunakan.

- Software CodeVisionAvr

Fitur-fitur yang dimiliki CodeVisionAVR terbilang lengkap. Software ini menyediakan interface hyperterminal didalamnya. Hyperterminal ini dapat digunakan untuk berkomunikasi antara mikrokontroler dengan komputer. Untuk proses pembakaran atau pengisian program ke dalam mikrokontroler terdapat tool tersendiri.

Bahasa pemrograman yang digunakan ialah bahasa C. Bahasa ini dipakai karena lebih mudah dimengerti. Namun penggunaan untuk beberapa akses ke mikrokontroler juga membutuhkan code dalam bahasa assembly. Kelebihan yang dimiliki CodeVisionAVR adalah dapat dimasukkannya code assembly dalam code $\mathrm{C}$.

- Software Terra Term 
Untuk memasukkan perintah yang ditekan user dari keyboard menggunakan software terra term, software terra term digunakan selain karena pengoprasiannya mudah software ini open source dapat diperoleh dan digunakan secara gratis tanpa perlu membayar lisensi.

\section{IMPLEMENTASI DAN PEMBAHASAN}

\subsection{Implementasi}

Dalam implementasi menjelaskan tentang rangkain elektronika, pemrograman ke mikrokontroler, serta konfigurasi software pada PC.

- Rangkaian Elektronika Mobile Robot

Rangkaian Elektronika mobile robot terdiri dari, rangkaian board mobile robot, rangkaian mikrokontroler mobile robot, rangkaian serial bluetooth mobile robot dan rangkaian twin gearbox mobile robot.

- Rangkaian Board Mobile Robot

Dalam pembuatan mobile robot ini menggunakan board arduino, board arduino yang digunakan terpasang mikrokontroler ATmega8.

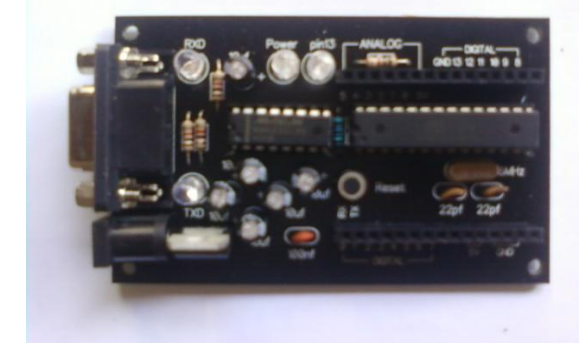

Gambar 4.4 Board Arduino

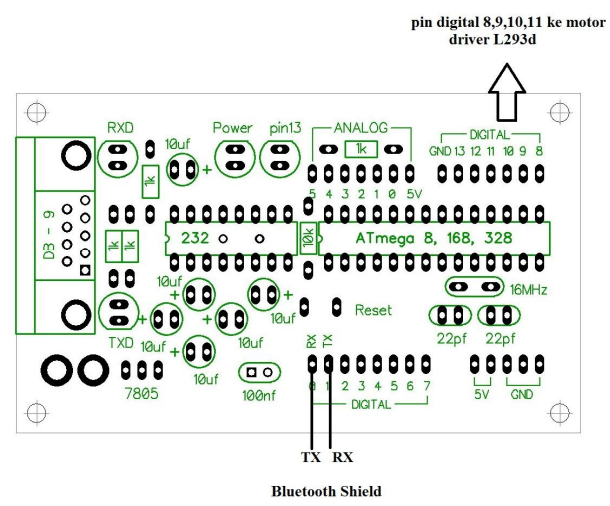

Gambar 4.5 Konfigurasi Pin

Konfigurasi arduino board yaitu pin Receiver (RX) terhubung ke pin Transmitter (TX) Bluetooth Shield dan Transmitter (TX) erulduino board terhubung ke Receiver (RX) Bluetooth Shield. Dan selanjutnya pin digital 8,9,10 dan 11 terhubung ke motor driver L293d.

- Rangkaian Bluetooth 
ISSN 2089-8673

Jurnal Nasional Pendidikan Teknik Informatika (JANAPATI)

Volume 2, Nomor 1, Maret 2013

Pada mobile robot digunakan bluetooth shield V2.2, dimana modul bluetooth dengan serial port dan compatible dengan arduino board. menggunakan pin D0, D1, D4-D7 sebagai pin UART, bluetooth shield ini dapat berkomunikasi dengan board arduino, dan sangat mudah untuk merubah pengaturannya menggunakan AT command melalui USB. Terdapat switch untuk merubah koneksi module, pada posisi switch "To Board".

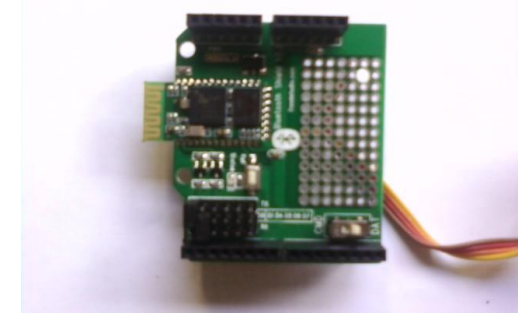

Gambar 4.6 Bluetooth Shield V2.2

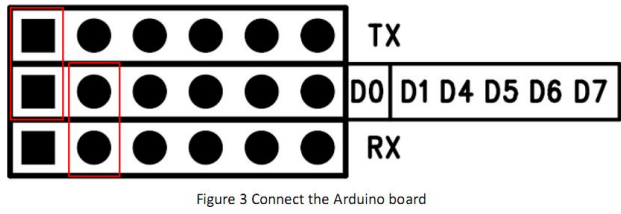

Gambar 4.7 Pin Bluetooth

- IC Driver Motor

Dengan memanfaatkan sebuah IC Driver Motor 1Amp yang bernama L293D. berikut ini merupakan konfigurasi dari pin L293d yang digunakan pada mobile robot:

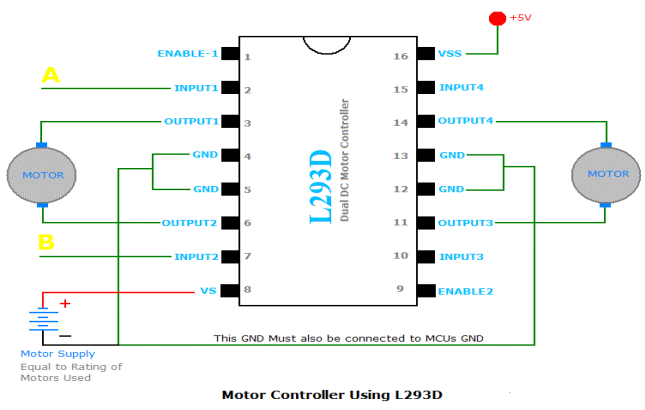

Gambar 4.8 IC Driver Motor

IC driver L293d memiliki empat buah output yang nantinya terhubung ke motor. Kemudian adanya empat buah input yang langsung dikontrol dengan mikrokontroler. Input tegangan motor ini masuk ke pin 8 seperti terlihat dalam konfigurasi pin seperti gambar berikut ini.

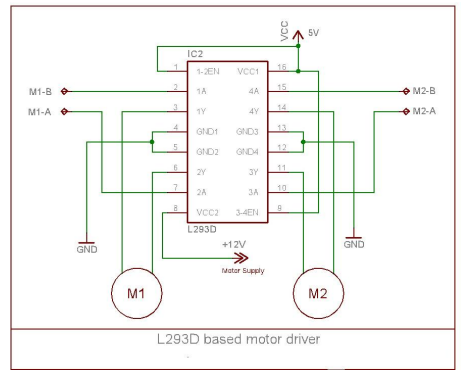


ISSN 2089-8673

Jurnal Nasional Pendidikan Teknik Informatika (JANAPATI)

Volume 2, Nomor 1, Maret 2013

Gambar 4.9 Konfigurasi Pin IC Driver

Pin M1-B ke pin digital 8 board

Pin M1-A ke pin digital 9 board

Pin M2-B ke pin digital 10 board

Pin M1-A ke pin digital 11 board

- Rangkaian Twin Gearbox Motor Dc

Pada bagian penggeraknya menggunakan satu set twin gearbox motor milik Tamiya berikut ini gambar twin gearbox beserta ukuran dimensinya.

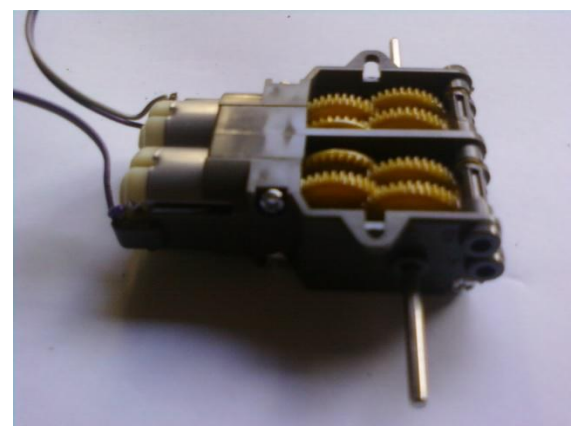

Gambar 4.10 Motor Dc

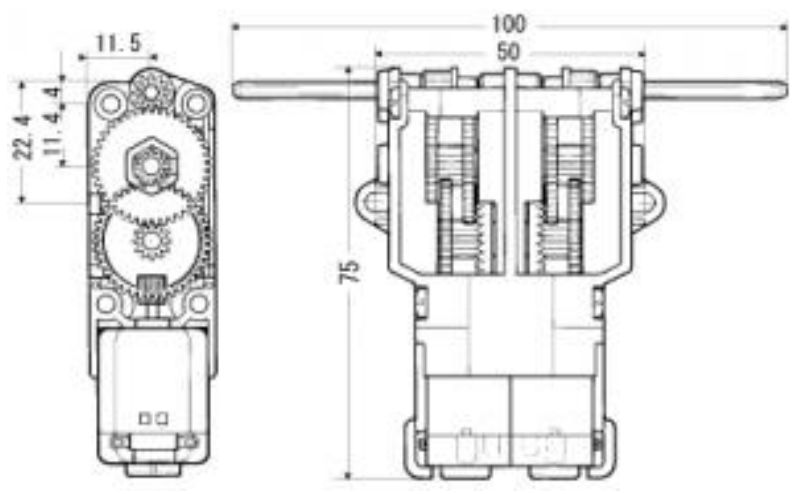

Gambar 4.11 Ukuran Dimensi Twin Gearbox

Penempatan dari twin gearbox berada pada posisi belakang sehingga apabila mobile robot berjalan maju atau mundur titik tumpuan dari berat 
ISSN 2089-8673

Jurnal Nasional Pendidikan Teknik Informatika (JANAPATI)

Volume 2, Nomor 1, Maret 2013

badan robot tepat berada di tengah, hal ini sangat penting untuk menjaga keseimbangan mobile robot saat berjalan.

- Pemrograman Mobile Robot

Pemrograman mikrokontroler pada mobile robot menggunakan bahasa $\mathrm{C}$. dimana dalam pemasukan program dari PC menggunakan kabel usb to serial yang dimasukkan pada serial max 232 .

Berikut lis programnya

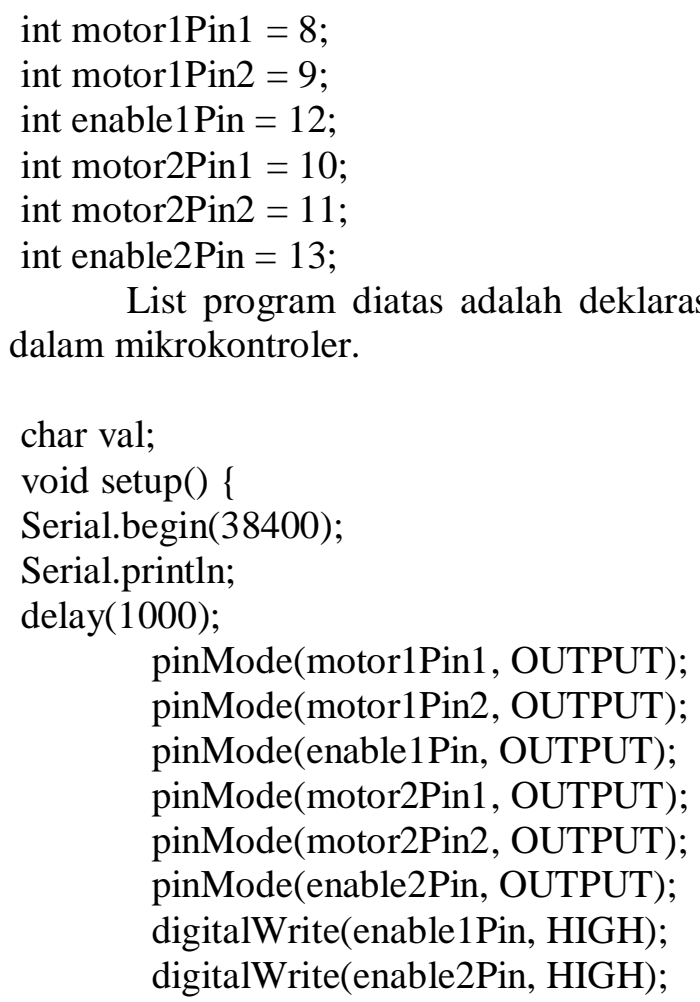
dalam mikrokontroler.

char val;

void $\operatorname{setup}()\{$

Serial.begin(38400);

Serial.println;

$\operatorname{delay}(1000)$;

pinMode(motor1Pin1, OUTPUT);

pinMode(motor1Pin2, OUTPUT);

pinMode(enable1Pin, OUTPUT);

pinMode(motor2Pin1, OUTPUT);

pinMode(motor2Pin2, OUTPUT);

pinMode(enable2Pin, OUTPUT);

digitalWrite(enable1Pin, HIGH);

digitalWrite(enable2Pin, HIGH);

List program diatas adalah deklarasi pin, sebagai informasi yang diolah

\}

List program diatas adalah saat mobile robot pertama mulai dihidupkan.

Pemberian nilai pada setiap pin.

void $\operatorname{loop}()\{$

if (Serial.available ()$)\{$

val= Serial.read () ;

\}

Lits program diatas berjalan berulang $\ddot{i}$ ulang list program ini digunakan dalam serial bluetooth.

if $(\mathrm{val}==$ ' $w$ ') \{

digitalWrite(motor1Pin1, LOW);

digitalWrite(motor1Pin2, HIGH);

digitalWrite(motor2Pin1, LOW);

digitalWrite(motor2Pin2, HIGH);

Serial.println("maju"); 
ISSN 2089-8673

Jurnal Nasional Pendidikan Teknik Informatika (JANAPATI)

Volume 2, Nomor 1, Maret 2013

List program diatas untuk mengontrol mobile robot bergerak maju. Jika tombol ñwò yang di tekan pada keyboard maka mobile robot akan bergerak maju.

\} else if $(\mathrm{val}==$ ' $\mathrm{s}$ ')

digitalWrite(motor1Pin1, LOW);

digitalWrite(motor1Pin2, LOW);

digitalWrite(motor2Pin1, LOW);

digitalWrite(motor2Pin2, LOW);

Serial.println("berhenti");

List program diatas untuk mengontrol mobile robot agar berhenti bergerak. Jika tombol ñsò yang di tekan pada keyboard maka mobile robot akan berhenti bergerak.

\}else if $(\mathrm{val}==\mathbf{a})\{$

digitalWrite(motor1Pin1, HIGH);

digitalWrite(motor1Pin2, LOW);

digitalWrite(motor2Pin1, LOW);

digitalWrite(motor2Pin2, HIGH);

Serial.println("kiri");

List program diatas untuk mengontrol mobile robot bergerak ke kiri. Jika tombol ñaòyang di tekan pada keyboard maka mobile robot akan bergerak ke kiri.

\}else if $($ val $==$ 'd') \{

digitalWrite(motor1Pin1, LOW);

digitalWrite(motor1Pin2, HIGH);

digitalWrite(motor2Pin1, HIGH);

digitalWrite(motor2Pin2, LOW);

Serial.println("kanan");

List program diatas untuk mengontrol mobile robot bergerak ke kanan. Jika tombol ñdò yang di tekan pada keyboard maka mobile robot akan bergerak kekanan.

\}else if (val == 'z') \{

digitalWrite(motor1Pin1, HIGH);

digitalWrite(motor1Pin2, LOW);

digitalWrite(motor2Pin1, HIGH);

digitalWrite(motor2Pin2, LOW);

Serial.println("mundur");

\}

\}

List program diatas untuk mengontrol mobile robot bergerak mundur. Jika tombol ñzò yang di tekan pada keyboard maka mobile robot akan bergerak mundur.

\subsection{Pembahasan}

mobile robot.

Dalam pembahasan meliputi pengujian koneksi dan pengujian pergerakan 
ISSN 2089-8673

Jurnal Nasional Pendidikan Teknik Informatika (JANAPATI)

Volume 2, Nomor 1, Maret 2013

- Pengujian Koneksi

Pengujian koneksi dilakukan untuk mengetahui adanya pertukaran data antara mobil robot dan PC. Pengujian ini dilakukan dengan memasang USB Bluetooth pada PC. jika usb bluetooth telah dipasang maka icon bluetooth akan muncul pada task bar kanan bawah PC. selanjutnya mobile robot yang telah dihidupkan akan melakukan pencarian ke usb bluetooth PC yang ditandai dengan kedipan lampu pada serial bluetooth mobile robot dalam durasi yang cepat. Jika PC dan mobile robot telah terhubung maka lampu pada serial bluetooth mobile robot akan berkedip lamban. selanjutnya dilakukan konfigurasi pada software bawaan bluetooth dengan memasukkan password yang telah ditentukan. Pemberian password pada mobile robot dimaksudkan agar mobile robot tidak bisa dikendalikan oleh user lain saat pengoperasian.

- Pengujian Pergerakkan

Pada tahap pengujian pergerakan mobile robot dilakukan pengukuran kecepatan mobile robot dengan jarak satu meter, dimana pengukuran ini adalah untuk mengetahui berapa waktu yang diperlukan saat mobile robot bergerak lurus. Pada tahap pengukuran ini akan dilakukan secara berulang ï ulang agar mendapatkan hasil yang akurat.

4.3 Penjabaran Hasil Uji

Dalam penjabaran hasil uji meliputi pengjujian koneksi dan pergerakan mobile robot.

- Pengujian Koneksi Mobile Robot

Konfigurasi pada software dengan memasukkan password :

Tabel 4.1 Pengujian Dengan Password

\begin{tabular}{|l|l|}
\hline \multicolumn{2}{|c|}{ Kasus } \\
\hline Data masukkan & Password bluetooth mobile robot \\
\hline Yang diharapkan & $\begin{array}{l}\text { User dapat memasukkan password, akan terjadi } \\
\text { pengecekan pada mobile robot, jika password benar } \\
\text { mobile robot } \text { akan mengirim data serial port dimana } \\
\text { yang nanti digunakan untuk mengendalikan mobile } \\
\text { robot }\end{array}$ \\
\hline Pengamatan & Dapat mengisi password sesuai yang diharapkan \\
\hline kesimpulan & Sukses \\
\hline
\end{tabular}

Konfigurasi pada software tanpa memasukkan password :

Tabel 4.2 Pengujian Tanpa Password

\begin{tabular}{|l|l|}
\hline \multicolumn{2}{|c|}{ Kasus } \\
\hline Data masukkan & Tanpa memasukkan password \\
\hline Yang diharapkan & $\begin{array}{l}\text { Tidak adanya pertukaran data antara PC dan mobile } \\
\text { robot yang ditandai dengan tidak adanya konfirmasi } \\
\text { dari device } \text { mobile robot. }\end{array}$ \\
\hline Pengamatan & Mobile robot tidak dapat dikendalikan \\
\hline kesimpulan & Sukses \\
\hline
\end{tabular}


ISSN 2089-8673

Jurnal Nasional Pendidikan Teknik Informatika (JANAPATI)

Volume 2, Nomor 1, Maret 2013

- Pengujian Pergerakan Mobile Robot

Pengujian waktu tempuh rata Ï rata mobile robot bergerak maju

Tabel 4.3 Waktu Tempuh Rata - Rata Mobile Robot bergerak maju

\begin{tabular}{|c|c|c|}
\hline Percobaan & Jarak Tempuh (s) & Waktu Tempuh (t) \\
\hline 1 & 1 Meter & 6,25 detik \\
\hline 2 & 1 Meter & 6.54 detik \\
\hline 3 & 1 Meter & 6,44 detik \\
\hline 4 & 1 Meter & 6,57 detik \\
\hline 5 & 1 Meter & 6,59 detik \\
\hline 6 & 1 Meter & 6,52 detik \\
\hline 7 & 1 Meter & 6,45 detik \\
\hline 8 & 1 Meter & 6,43 detik \\
\hline 9 & 1 Meter & 6,53 detik \\
\hline 10 & 1 Meter & 6,20 detik \\
\hline 11 & 1 Meter & 6,57 detik \\
\hline 12 & 1 Meter & 6,42 detik \\
\hline 13 & 1 Meter & 6,58 detik \\
\hline 14 & 1 Meter & 6,28 detik \\
\hline 15 & 1 Meter & 6,53 detik \\
\hline 16 & 1 Meter & 6,55 detik \\
\hline 17 & 1 Meter & 6,50 detik \\
\hline 18 & 1 Meter & 6,31 detik \\
\hline 19 & 1 Meter & 6,45 detik \\
\hline 20 & 1 Meter & 6,52 detik \\
\hline 21 & 1 Meter & 6,54 detik \\
\hline 22 & 1 Meter & 6,40 detik \\
\hline 23 & 1 Meter & 6,55 detik \\
\hline 24 & 1 Meter & 6,53 detik \\
\hline 25 & 1 Meter & 6,25 detik \\
\hline 26 & 1 Meter & 6,56 detik \\
\hline 27 & 1 Meter & 6,41 detik \\
\hline 28 & 1 Meter & 6,50 detik \\
\hline 29 & 1 Meter & 6,46 detik \\
\hline 30 & 1 Meter & 6,54 detik \\
\hline 31 & 1 Meter & 6,49 detik \\
\hline 32 & 1 Meter & 6,55 detik \\
\hline 33 & 1 Meter & 6,46 detik \\
\hline 34 & 1 Meter & 6,59 detik \\
\hline 35 & 1 Meter & 6,58 detik \\
\hline 36 & 1 Meter & 6,46 detik \\
\hline 37 & 1 Meter & 6,54 detik \\
\hline 38 & 1 Meter & 6,57 detik \\
\hline
\end{tabular}




\begin{tabular}{|l|l|l|}
\hline 39 & 1 Meter & 6,51 detik \\
\hline 40 & 1 Meter & 6,46 detik \\
\hline 41 & 1 Meter & 6,52 detik \\
\hline 42 & 1 Meter & 6,58 detik \\
\hline 43 & 1 Meter & 6,56 detik \\
\hline 44 & 1 Meter & 6,51 detik \\
\hline 45 & 1 Meter & 6,59 detik \\
\hline 46 & 1 Meter & 6,50 detik \\
\hline 47 & 1 Meter & 6,46 detik \\
\hline 48 & 1 Meter & 6,58 detik \\
\hline 49 & 1 Meter & 6,52 detik \\
\hline 50 & 1 Meter & 6,56 detik \\
\hline & Rata - rata & $\mathbf{6 , 4 9}$ detik \\
\hline
\end{tabular}

Waktu tempuh rata $\ddot{i}$ rata mobile robot bergerak maju adalah 6,49 detik dalam jarak 1 meter. Maka didapat kecepatan rata $і$ rata mobile robot adalah :

$\mathrm{v}=\operatorname{Kecepatan}(\mathrm{m} / \mathrm{s})$

$\mathrm{s}=\operatorname{Jarak}$ tempuh $(\mathrm{m})$

$\mathrm{t}=$ Waktu tempuh $(\mathrm{s})$

$$
\mathrm{v}=\frac{\mathrm{s}}{\mathrm{t}}=\frac{1 \text { Meter }}{6,49 \text { detik }}=0,154 \mathrm{~m} / \mathrm{s}
$$

Jadi kecepatan rata ï rata dari mobile robot adalah $0,154 \mathrm{~m} / \mathrm{s}$

Pengujian waktu putaran ke kanan mobile robot pada sumbu $360^{\circ}$

Tabel 4.3 Waktu Putaran ke kanan Mobile Robot

\begin{tabular}{|l|l|l|}
\hline Percobaan & \multicolumn{1}{|c|}{ Putaran } & \multicolumn{1}{c|}{ Waktu } \\
\hline 1 & $360^{\circ}$ & 2,49 detik \\
\hline 2 & $360^{0}$ & 2,51 detik \\
\hline 3 & $360^{0}$ & 2,44 detik \\
\hline 4 & $360^{0}$ & 2,39 detik \\
\hline 5 & $360^{0}$ & 2,50 detik \\
\hline 6 & $360^{0}$ & 2,43 detik \\
\hline 7 & $360^{0}$ & 2,48 detik \\
\hline 8 & $360^{0}$ & 2,44 detik \\
\hline 9 & $360^{0}$ & 2,47 detik \\
\hline 10 & $360^{0}$ & 2,49 detik \\
\hline 11 & $360^{0}$ & 2,46 detik \\
\hline 12 & $360^{0}$ & 2,54 detik \\
\hline 13 & $360^{0}$ & 2,47 detik \\
\hline 14 & $360^{0}$ & 2,43 detik \\
\hline
\end{tabular}


ISSN 2089-8673

Jurnal Nasional Pendidikan Teknik Informatika (JANAPATI)

Volume 2, Nomor 1, Maret 2013

\begin{tabular}{|c|c|c|}
\hline 15 & $360^{0}$ & 2,48 detik \\
\hline 16 & $360^{0}$ & 2,45 detik \\
\hline 17 & $360^{\circ}$ & 2,54 detik \\
\hline 18 & $360^{\circ}$ & 2,47 detik \\
\hline 19 & $360^{\circ}$ & 2,43 detik \\
\hline 20 & $360^{\circ}$ & 2,48 detik \\
\hline 21 & $360^{\circ}$ & 2,50 detik \\
\hline 22 & $360^{\circ}$ & 2,44 detik \\
\hline 23 & $360^{\circ}$ & 2,45 detik \\
\hline 24 & $360^{\circ}$ & 2,48 detik \\
\hline 25 & $360^{\circ}$ & 2,51 detik \\
\hline 26 & $360^{\circ}$ & 2,56 detik \\
\hline 27 & $360^{0}$ & 2,53 detik \\
\hline 28 & $360^{\circ}$ & 2,48 detik \\
\hline 29 & $360^{\circ}$ & 2,51 detik \\
\hline 30 & $360^{\circ}$ & 2,53 detik \\
\hline 31 & $360^{\circ}$ & 2,50 detik \\
\hline 32 & $360^{\circ}$ & 2,52 detik \\
\hline 33 & $360^{\circ}$ & 2,49 detik \\
\hline 34 & $360^{\circ}$ & 2,46 detik \\
\hline 35 & $360^{\circ}$ & 2,47 detik \\
\hline 36 & $360^{\circ}$ & 2,54 detik \\
\hline 37 & $360^{0}$ & 2,45 detik \\
\hline 38 & $360^{\circ}$ & 2,49 detik \\
\hline 39 & $360^{\circ}$ & 2,47 detik \\
\hline 40 & $360^{\circ}$ & 2,51 detik \\
\hline 41 & $360^{\circ}$ & 2,48 detik \\
\hline 42 & $360^{\circ}$ & 2,46 detik \\
\hline 43 & $360^{0}$ & 2,52 detik \\
\hline 44 & $360^{\circ}$ & 2,50 detik \\
\hline 45 & $360^{\circ}$ & 2,46 detik \\
\hline 46 & $360^{0}$ & 2,51 detik \\
\hline 47 & $360^{\circ}$ & 2,53 detik \\
\hline 48 & $360^{\circ}$ & 2,48 detik \\
\hline 49 & $360^{\circ}$ & 2,46 detik \\
\hline 50 & $360^{0}$ & 2,50 detik \\
\hline \multicolumn{2}{|r|}{ Rata - rata } & 2,48 detik \\
\hline
\end{tabular}

Dari tabel diatas dapat dilihat, waktu rata ï rata yang diperlukan mobile robot untuk melakukan putaran sebesar $360^{\circ}$ adalah 2,48 detik.

\section{KESIMPULAN DAN SARAN}

\subsection{Kesimpulan}


ISSN 2089-8673

Jurnal Nasional Pendidikan Teknik Informatika (JANAPATI)

Volume 2, Nomor 1, Maret 2013

Berdasarkan hasil penelitian terhadap masalah yang dibahas dalam makalah ini, dapat ditarik beberapa kesimpulan seperti :

1. Perancangan mobile robot meliputi perancangan desain body mobile robot, perancangan rangkaian elektronika dan pemrograman ke mikrokontroler sehingga mobile robot dapat dikendalikan user.

2. Teknologi bluetooth yang digunakan sebagai koneksi mobile robot meliputi serial bluetooth Shield V2.2 yang dipasang pada mobile robot dan usb bluetooth yang dipasang pada PC. selanjutnya melakukan konfigurasi software bluetooth sehingga mobile robot dan PC saling terhubung.

3. Kecepatan rata $\ddot{i}$ rata dari mobile robot bergerak maju adalah $0,154 \mathrm{~m} / \mathrm{s}$ dengan jarak tempuh 1 meter.

4. Waktu rata ï rata yang diperlukan mobile robot untuk melakukan putaran ke kanan sebesar $360^{\circ}$ adalah 2,48 detik.

\subsection{Saran}

Adapun saran yang dapat disampaikan untuk pengembangan mobile robot ini seperti :

1. Penambahan kamera pada mobile robot, sehingga mobile robot ini dapat menyerupai robot pengintai.

2. Penambahan sensor jarak, sehingga saat ada halangan yang tidak terlihat mobile robot dapat menghindar dari benturan.

3. Mengganti bluetooth dengan teknologi koneksi lain yang memiliki jarak jangkauan lebih jauh.

\section{DAFTAR PUSTAKA}

Budiharto, Widodo. 2010. Robotika Teori dan Implementasi. Yogyakarta: Andi

Jogiyanto. 2005. Pengenalan Komputer. Yogyakarta: Andi

Rangkuti, Syahban. 2011. Mikrokontroller Atmel AVR. Bandung: INFORMATIKA

Maisuradze, Boris. 2004. Tera Term Development and Support.

http://www.logmett.com. Diakses pada tanggal 20 Juli 2012

Supriyanto, Aji. 2006. Tinjuan Teknis Teknologi Perangkat Wireless dan Standar Keamananya. Semarang: Universitas Stikubank

Suyadhi, Taufiq Dwi Septian. 2008. Build Your Own Line Follower ROBOT. Yogyakarta: Andi

Zaki, Ali. 2010. Panduan Hardware Komputer. Yogyakarta: Andi 